\title{
PEDAGOGICAL ASPECTS OF SPIRITUAL AND PRACTICAL ASSIMILATION OF REALITY TO MORALITY
} (C) 2016

O.K. Pozdnyakova, doctor of pedagogical sciences, professor, corresponding member of Russian Academy of Education, professor of the Pedagogy and Psychology Department Samara State University of Social Sciences and Education, Samara (Russia)

Abstract. The paper considers the necessity of thinking about morality as a means of spiritual and practical development of human reality in the context of pedagogical knowledge. It is argued that the spiritual and practical assimilation of reality is carried out with the participation of the moral consciousness and the methods of social orientation in the human world, the world of values are in its functioning mechanisms. The author reveals the relationship of morality and moral consciousness. Morality can be found in behavior and actions, in activities and actions, in human relationships. The moral consciousness, consisting of ideas, opinions, estimates, allows you to make the choice of actions and activities that are implemented in behavior and activities. The author differentiates morality and ethics: morality is objective and ethics are subjective. It is proved that the moral consciousness of the teachers involved in the spiritual and practical assimilation of reality to morality is an ideal that in a certain way organizes and regulates his or her actions on education and training of children. It has been established that the spiritual and the practical reality in the development of morality takes place on the basis of moral consciousness in which deontological and axiological, evaluative and motivational are in unity and relationships. The teacher realizing axiological and deontological through familiarizing students to the values, achieving the purpose of education, develops the double motivation of students, the essence of which lies in the unity of the deontological and axiological aspects of the spiritual and practical assimilation of reality to morality.

Keywords: teacher; student; moral; spiritual and practical mastery of reality; moral consciousness; moral consciousness; morality; value; pedagogical reflection; educational activities; actions; behavior; evaluation; motivation; attitudes; choices.

УДК 378.14

\section{МОДЕЛЬ СИСТЕМЫ ФОРМИРОВАНИЯ У СТУДЕНТОВ ПРОФЕССИОНАЛЬНОЙ ЭКСПЕРИМЕНТАЛЬНО-ИССЛЕДОВАТЕЛЬСКОЙ КОМПЕТЕНЦИИ}

\section{(C) 2016}

Д.В. Попов, старший преподаватель кафедры общей физики и физики нефтегазового производства Самарский государственный технический университет, Самара (Россия)

Аннотация. В статье представлены результаты исследования по разработке и реализации педагогической системы формирования у студентов технического университета профессиональных экспериментально-исследовательских компетенций в процессе перманентного выполнения ими комплекса лабораторных работ. Проблема и ее решение рассматриваются на примере подготовки специалистов по специальности «Физические процессы в нефтегазовом производстве». Показана роль и место лабораторного исследовательского эксперимента в компетентностной парадигме профессиональной подготовки специалистов по физическим процессам нефтегазового производства.

Дана авторская трактовка понятия «профессиональная экспериментально-исследовательская компетенция», определены ее функциональные и содержательные компоненты.

В статье представлена теоретическая модель педагогической системы формирования у студентов профессиональных экспериментально-исследовательских компетенций в процессе выполнения лабораторных исследовательских экспериментов, которая является алгоритмом и системным навигатором для разработчиков и пользователей аналогичных систем.

Разработаны дескрипторы функциональных и содержательных компонентов (когнитивного, операционального, деятельностного), которые используются в качестве критериев оценки уровней сформированности у студентов профессиональной экспериментально-исследовательской компетенции.

Рассматривается содержание и структура информационно-дидактической базы формирования профессиональной экспериментально-исследовательской компетенции, доминирующее место в которой занимает комплекс лабораторных работ по физике и физическим процессам нефтегазового производства.

Приведены результаты проведенного констатирующего и формирующего экспериментов по выявлению исходного и итогового уравнений сформированности у студентов экспериментальной и контрольной групп, свидетельствующие о целесообразности и высокой эффективности использования инновационной компетентностно-модульной технологии проведения лабораторных экспериментально-исследовательских работ.

Ключевые слова: профессиональная экспериментально-исследовательская компетенция; нефтегазовое производство; система формирования профессиональной компетенции; компетентностно-модульная технология; информационно-дидактическая база; лабораторно-экспериментальная работа; критерий уровня сформированности. 
Лидирующее положение нашей страны на мировом рынке нефтегазовой продукции, все возрастающие требования к её качеству актуализировали проблему подготовки специалистов нового профиля горных инженеров по физическим процессам нефтегазового производства.

Весьма существенно, что Федеральный государственный образовательный стандарт высшего профессионального образования подготовки специалистов по специальности 13.12.01 Физические процессы горного или нефтегазового дела определил в качестве результата освоения студентами основной образовательной программы - сформированные у них совокупности общекультурных и профессиональных компетенций. В совокупности представленных в этом стандарте компетенций содержится профессиональная компетенция под номером ПК-23, которую можно правомерно назвать профессиональной экспериментально-исследовательской компетенцией.

Эта компетенция дословно трактуется, как его готовность выполнять экспериментальные исследования в натурных и лабораторных условиях с использованием современных методов и средств измерения, как его готовность обрабатывать и интерпретировать полученные в эксперименте результаты, составлять и защищать отчеты [2;3].

Это лаконично сформулированная дефиниция ПЭИК в самом общем виде отражает готовность выпускника вуза выполнять экспериментальные исследования в лабораторных и натурных условиях, но не в полной мере учитывает структуру и содержание многокомпонентного процесса выполнения лабораторной экспериментально-исследовательской работы, что является барьером в проектировании инновационной технологии проведения лабораторной работы и разработке средств контроля и оценки уровней сформированности ПЭИК. В связи с этим стандартизированная формулировка дефиниции была расширена, дополнена, уточнена и обоснована $[4 ; 5]$. При этом в авторской трактовке под термином «профессиональная экспериментально-исследовательская компетенция» понимается интегративная многокомпонентная субстанция, адекватно отражающая его готовность на основе приобретенных знаний, умений, навыков и личностных профессионально-значимых качеств планировать и подготавливать лабораторный либо натурный эксперимент, корректно и адекватно цели и задачам эксперимента выполнять комплекс мыследеятельностных, психомоторных и тактильных операций и процедур, выполнять статистическую обработку и оценку полученных данных, эффективно и аргументированно проводить их презентацию/защиту [6; 7].

С целью эффективного развития и системного формирования у студентов профессиональной экспериментально-исследовательской компетенции в процессе выполнения ими учебных лабораторных работ была разработана на качественном уровне теоретическая модель системы формирования ПЭИК (рис. 1). Из рисунка видно, что в структуре системы содержится одиннадцать взаимосвязанных звеньев. Звено целеполагания (1) отражает целевое предназначение педагогической системы: формирование у студентов ПЭИК в процессе выполнения ими учебных экспериментально-лабораторных работ. Звено 2 модели системы, раскрывает содержание и компонентный состав ПЭИК

Любая компетенция, в том числе и ПЭИК, имеет сложную внутреннюю интегративную структуру с большим числом компонентов разной природы. Для решения рассматриваемой проблемы необходимо и достаточно учитывать лишь содержательные и функциональные компоненты ПЭИК. Содержательные компоненты (когнитивный, операциональный и деятельностный) позволяют опосредовано контролировать, измерять и оценивать уровни сформированности ПЭИК. Функциональные компоненты отражают этапы и виды экспериментально-исследовательской деятельности студентов в процессе выполнения лабораторных работ. Здесь также три взаимосвязанных и преемственно реализуемых компонента: ККП - планирование и подготовка физического лабораторного эксперимента; ККВ - собственно процесс выполнения экспериментально-исследовательской лабораторной работы; ККОО - статистическая обработка экспериментальных данных и презентация результатов эксперимента [8].

Матрица дескриторов содержательных и функциональных компонентов ПЭИК представлена в табл. 1.

Таблица 1 - Дескриторы функциональных и содержательных компонентов ПЭИК

\begin{tabular}{|c|c|c|c|}
\hline \multirow{2}{*}{$\begin{array}{c}\text { Функциональные } \\
\text { компоненты ПЭИК }\end{array}$} & \multicolumn{3}{|c|}{ Содержательные компоненты ПЭИК } \\
\hline & Когнитивный & Операциональный & Деятельн \\
\hline $\begin{array}{l}\text { ККП - планирова- } \\
\text { ние и подготовка } \\
\text { лабораторного экс- } \\
\text { перимента }\end{array}$ & $\begin{array}{l}\text { Знание теоретических основ } \\
\text { планирования эксперимента, } \\
\text { знание инструментальных } \\
\text { средств контроля и измерения }\end{array}$ & $\begin{array}{l}\text { Умение составлять планы } \\
\text { проведения физического } \\
\text { эксперимента, выбора ин- } \\
\text { струментальных средств }\end{array}$ & $\begin{array}{l}\text { Владение техникой расчета } \\
\text { многофакторных физиче- } \\
\text { ских экспериментов. Оце- } \\
\text { нивание готовности ин- } \\
\text { струментальных средств }\end{array}$ \\
\hline $\begin{array}{l}\text { ККВ - процесс вы- } \\
\text { полнения экспери- } \\
\text { ментально- } \\
\text { исследовательской } \\
\text { работы }\end{array}$ & $\begin{array}{l}\text { Знание психомоторных опе- } \\
\text { раций проведения экспери- } \\
\text { мента, процедур наблюдения } \\
\text { и регистрации состояния и па- } \\
\text { раметров процесса, правил } \\
\text { обеспечения безопасности } \\
\text { эксперимента }\end{array}$ & $\begin{array}{l}\text { Умение выполнять психо- } \\
\text { моторные операции, про- } \\
\text { цедуры наблюдения и ре- } \\
\text { гистрации состояния и па- } \\
\text { раметров процесса, обеспе- } \\
\text { чивающие безопасность } \\
\text { проведения эксперимента }\end{array}$ & $\begin{array}{l}\text { Владение психомоторными } \\
\text { процедурами, техникой } \\
\text { наблюдения и регистрации } \\
\text { состояния и параметров } \\
\text { физического процесса, тех- } \\
\text { никой обеспечения без- } \\
\text { опасности проведения экс- } \\
\text { перимента }\end{array}$ \\
\hline $\begin{array}{l}\text { ККОО - статистиче- } \\
\text { ская обработка экс- } \\
\text { периментальных } \\
\text { данных и презента- } \\
\text { ция результатов } \\
\text { эксперимента }\end{array}$ & $\begin{array}{l}\text { Знание методов статистиче- } \\
\text { ской обработки эксперимен- } \\
\text { тальных данных. Знания спо- } \\
\text { собов и приемов эффективно- } \\
\text { го отображения и презентации } \\
\text { результатов эксперимента }\end{array}$ & $\begin{array}{l}\text { Умение выбора метода об- } \\
\text { работки эксперименталь- } \\
\text { ных данных, использова- } \\
\text { ния знаково-смысловой } \\
\text { наглядности представлен- } \\
\text { ных результатов }\end{array}$ & $\begin{array}{l}\text { Владение математическими } \\
\text { методами обработки экспе- } \\
\text { риментальных данных, } \\
\text { анализа, оценки и презен- } \\
\text { тации результатов экспе- } \\
\text { римента }\end{array}$ \\
\hline
\end{tabular}


Требования к уровням сформированности ПЭИК отражены в звене 3 модели системы. Предусмотрено три уровня сформированности: пороговый базовый), повышенный (углубленный), высокий $[9 ; 10]$.

Информативно-дидактическая база формирование ПЭИК включает в себя: содержание физических учебных дисциплин, содержание лабораторных работ, содержание учебной и производственной практик.

На основании этого был разработан учебно-методический комплекс по выполнению лабораторных работ студентами I-V курсов специальности «Физические процессы нефтегазового производства» [11; 12].
Компетентностно-модульная технология формирования ПЭИК (звено 5 модели системы) представлена в виде трех технологических модулей: модуль МП-подготовка и планирование лабораторного эксперимента; модуль МВ - выполнение операций и процедур, обеспечивающих получение необходимой и достаточной информации о состоянии и параметрах исследуемого объекта $[15 ; 16]$; модуль МОО - статистической обработки экспериментальных данных и презентации результатов эксперимента.

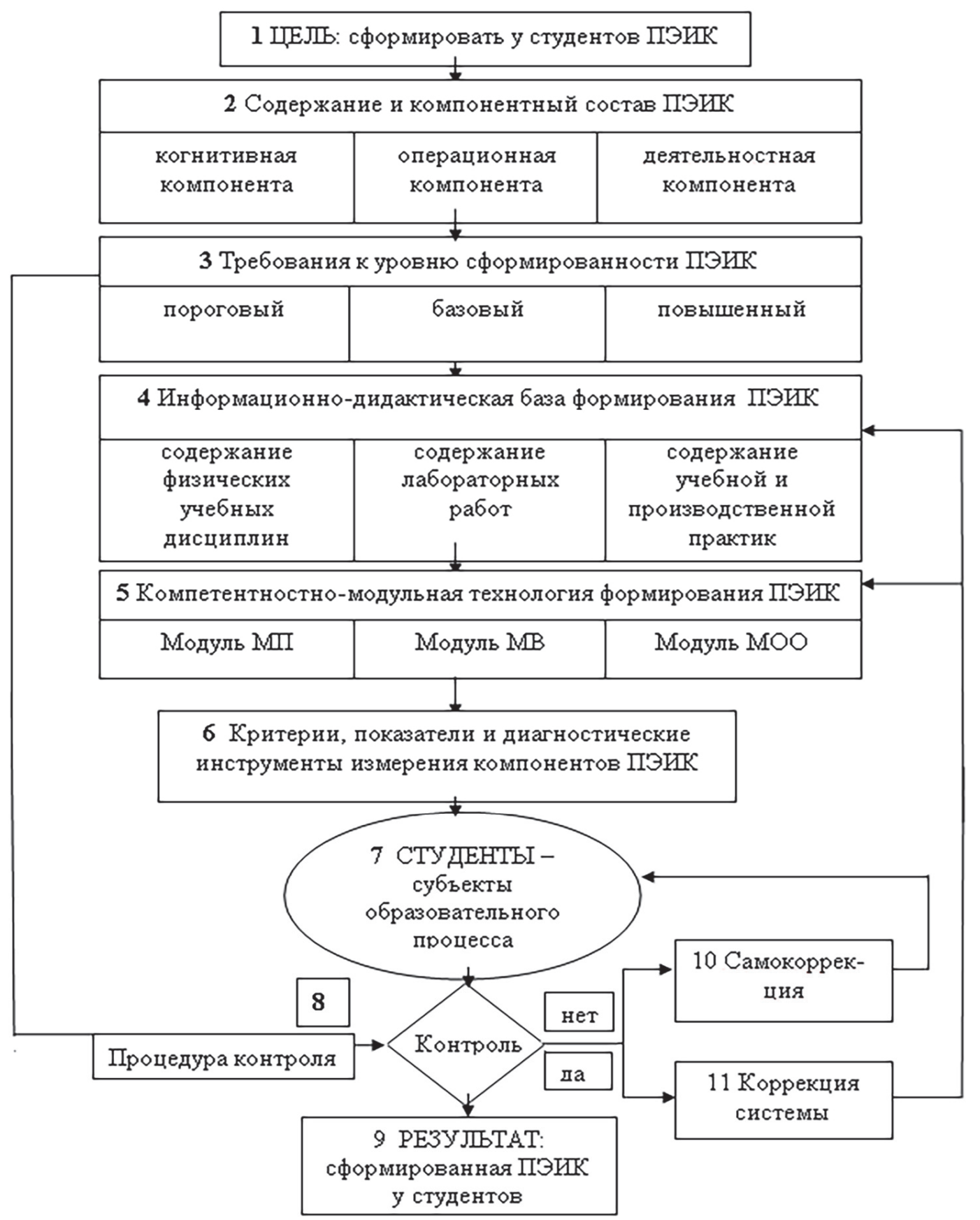

Рисунок 1 - Теоретическая модель системы формирования ПЭИК у студентов в процессе выполнения экспериментально-исследовательских лабораторных работ

Критериально-диагностическое звено 6 содержит критерии, показатели и средства контроля и оценки уровней сформированности компонентов ПЭИК $[17$; 18].

Звено 8 - процедура контроля, звено 9 - результат функционирования системы, звенья 10 и 11 - само- коррекция учебной деятельности студента и коррекции системы, соответственно.

Проведенные констатирующий и формирующий эксперименты по выявлению исходного и итогового уровней сформированности ПЭИК у студентов экспериментальной и контрольной групп позволили 
установить, что за счет перманентного выполнения студентами экспериментальной группы комплекса лабораторных работ по компетентностно-модульной технологии численность студентов со сформированной ПЭИК на высоком уровне возросла за период времени эксперимента (2012-2015 гг.) с 11\% до 48\%, т.е. в 4,4 раза, а на повышенном уровне с $14 \%$ до $37 \%$, т.е. в 2,6 раза $[19 ; 20]$.

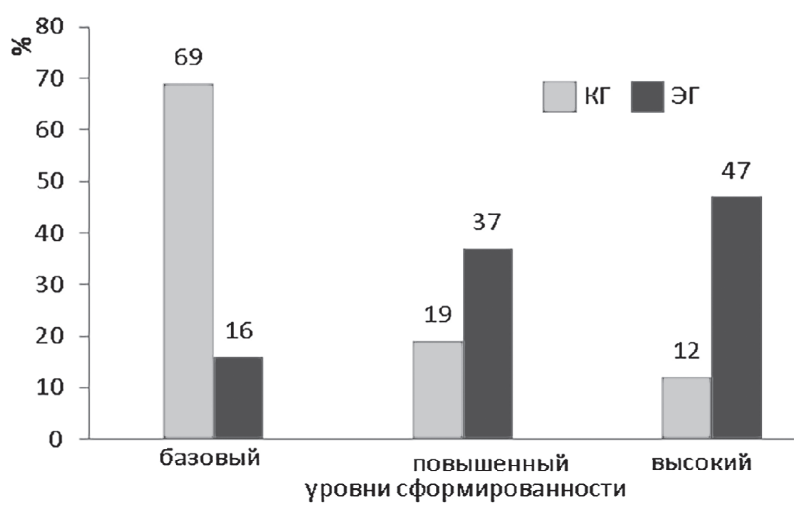

Рисунок 2 - Сравнительные диаграммы уровней сформированности компонентов ПЭИК у студентов контрольной и экспериментальной групп

Примерно такие же соотношения роста численности студентов экспериментальной группы (перманентно выполнявших лабораторные работы по инновационной компетентностно-модульной технологии) относительно численности студентов контрольной группы (выполнявших лабораторные работы по традиционной технологии) были получены на итоговом срезе формирующего эксперимента (рис. 2). Из приведенной на этом рисунке диаграммы следует, что на высоком уровне сформированности ПЭИК численность возросла в 4,0 раза, на повышенном - в 1,9 раза. Таким образом, многолетняя апробация и проведенный лонгитюдный педагогический эксперимент свидетельствующий о целесообразности и высокой эффективности использования компетентностно-модульной технологии выполнения лабораторных экспериментально-исследовательских работ.

\section{СПИСОК ЛИТЕРАТУРЫ:}

1. Летичевкая Н.Н., Егорова Е.В. Развитие профессионального образования в условиях взаимодействия вузов и предприятий нефтегазовой отрасли // Тезисы научно-практической конференции с международным участием. Самара: СГТУ, 2016. С. 19-20.

2. Федеральный государственный образовательный стандарт высшего профессионального образования по направлению подготовки (специальности) 13.12.01 - физические процессы горного и нефтегазового производства (квалификация «специалист»). М.: Минобрнауки РФ, 2010. 52 с. (№ 2050 от 24.12.2010).

3. Профессиональные стандарты в области информационных технологий. М.: Изд-во АПКИТ, 2008. $616 \mathrm{c}$.

4. Михелькевич В.Н., Попов Д.В., Валюженич М.К. Развитие универсальных и профессиональных компетенций у студентов в процессе проведения лабораторного физического эксперимента // Материалы Международной научно-практической конференции «Интеллектуальное развитие в процессе обучения физике». Самара: Изд-во ПГСГА, 2010. С. 133-142.
5. Михелькевич В.Н., Попов Д.В. Инновационный подход к проведению учебных лабораторных экспериментов по физике нефтегазовых производств // Технические университеты: интеграция с европейскими и мировыми системами образования: Материалы V-й международной конференции. Т. 1. Ижевск: Изд-во ИГТУ, 2012. С. 434-440.

6. Попов Д.В. Компетентностный подход к проведению лабораторных работ по физике в техническом вузе // Высокие интеллектуальные технологии и инновации в науке и образовании: Материалы XVII Meждународной конференции. СПб.: Изд-во СПбГПУ, 2010. С. 205-206.

7. Попов Д.В., Михелькевич В.Н. Формирование профессиональных экспериментально-исследовательских компетенций специалистов по физическим процессам нефтегазового производства // Материалы 3-й Всероссийской научно-методической конференции «Инновационные технологии профессионального образования». Т. 2. Грозный: ГГНТУ им. академика М.Д. Миллионщикова, 2012. С. 283-290.

8. Попов Д.В. Роль и место лабораторного эксперимента в компетентностной парадигме профессиональной подготовки специалистов нефтегазового производства // Вестник Самарского государственного технического университета. Серия «Педагогические науки». 2015. № 3 (27).

9. Новиков А.М. Методология образования. М.: ЭгВес. 2010. 320 c.

10. Морозов А.В., Чернилевский Д.В. Креативная педагогика и психология. М.: Академический проект, 2004. $560 \mathrm{c}$.

11. Штеренберг А.М., Попов Д.В. Методика обоснования тематики лабораторных работ по базовому курсу «Физика» для студентов специальности «Физические процессы нефтегазового производства» // Coвременные технологии подготовки кадров и повышения квалификации специалистов нефтегазового производства: Тезисы Международной научно-практической конференции. Самара: Изд-во СамГТУ, 2014. С. 77-78.

12. Михелькевич В.Н., Попов Д.В. Метод обоснования тематики лабораторных работ по физическим процессам нефтегазового производства // Традиции и инновации в строительстве: Материалы 70-й Всероссийской научно-практической конференции. Самара: Изд-во СГАСУ, 2013. С. 440-441.

13. Попов Д.В. Система развития у студентов-будущих специалистов по физическим процессам нефтегазового производства профессиональных компетенций в процессе выполнения лабораторно-экспериментальных работ // Научный журнал «Вестник Самарского государственного технического университета. Серия «Психолого-педагогические науки». 2014. № 2 (22). С. 158-171.

14. Михелькевич В.Н., Попов Д.В., Антонов Г.М. Деятельностный подход к формированию у курсантов личностных профессионально-значимых компетенций // Материалы Всероссийской научно-практической конференции «Правовое и духовно-нравственное воспитание российского офицерства». Самара: СЮИ ФСИН, 2015. С. 160-171. 
15. Михелькевич В.Н., Овчинникова Л.П. Учебный модуль-конструкт самоуправляемой дидактической системы формирования предметных компетенций // Вестник Самарского государственного технического университета. Серия Психолого-педагогические науки. 2011. № 1 (15). С. 83-88.

16. Капица П.Л. Эксперимент, теория, практика. М.: Изд-во «Наука», 1977. 351 с.

17. Кравцов П.Г., Михелькевич В.Н. Метод и средства измерения уровней сформированности функционально-профессиональных компетенций у выпускников технических вузов // Вестник Самарского государственного технического университета. Серия
«Психолого-педагогические науки». 2010. № 6 (14).

C. $125-130$

18. Коверялг А.А. Методы исследования в профессиональной педагогике. Вильнюс: Изд-во Валгус, 1980. 334 c.

19. Гуменникова Ю.В., Рябинова Е.Н., Черницына Р.Н. Статистическая обработка результатов тестирования студентов // Вестник Самарского государственного технического университета. Серия «Психолого-педагогические науки». 2015. № 3(27). С. 78-87.

20. Новиков Д.А. Статистические методы в педагогических исследованиях. М.: МЗ-Пресс, 2004. 67 с.

\title{
SYSTEM FORMATION MODEL OF STUDENTS' EXPERIMENTAL AND RESEARCH COMPETENCE
}

(C) 2016

\section{D.V. Popov, senior lecturer of the Chair of General Physics and Physics of Oil and Gas Production Samara State Technical University, Samara (Russia)}

Abstract. The article presents the research results of the formation model of students' professional experimental and research competences during performance of laboratory and experimental works. It explains the problem and solution of professional training of specialists in physical processes of oil and gas industry. It shows the meaning of laboratory and experimental works in competence paradigm of specialists in physical processes of oil and gas industry.

Here author represents such concept as «professional experimental and research competence» and defines its functionality and content components.

It points out the formation model of students' professional experimental and research competences during performance of laboratory and experimental works which is an algorithm and system navigator for developers and users of similar systems.

The author notes descriptors of functionality and content components which use such as criterion of the formation level of students' professional experimental and research competence.

The article points out the structure and content of the information and didactic basis based on the laboratory works complex in physical processes of oil and gas industry.

The article represents the results of ascertaining and forming experiment. It determines the initial and final equation of formation in experimental and control groups. It shows the feasibility and effectiveness of using high innovative competence modular technology of laboratory and experimental works.

Keywords: professional experimental and research competence; laboratory and physical experiment; oil and gas industry; system formation of professional competence; competence modular technology; information and didactic basis; laboratory and experimental work; criterion of the formation level.

УДК 378

\section{ФОРМИРОВАНИЕ НОРМ ПРОФЕССИОНАЛЬНОГО ПОВЕДЕНИЯ БУДУЩИХ ПЕРЕВОДЧИКОВ НА ЗАНЯТИИ-ПРОФИССЛЕДОВАНИИ В СИСТЕМЕ ВЫСШЕГО ОБРАЗОВАНИЯ}

(C) 2016

\author{
А.Н. Рыблова, доктор педагогических наук, профессор, \\ профессор кафедры лингвистики и межкультурной коммуникации \\ Российский новый университет, Москва (Россия)
}

\begin{abstract}
Аннотация. В статье поставлена актуальная проблема повышения качества практической подготовки кадров международного уровня, для решения которой автор предлагает формировать нормы профессионального поведения на занятии-профисследовании в системе высшего образования. На основе теоретико-методологического анализа работ отечественных и зарубежных ученых автор статьи предлагает модернизировать технологию организационного процесса исходя из запросов работодателей и индивидуальных потребностей обучающихся. При этом основным видом деятельности обучающихся на занятии-исследовании должна стать самостоятельная познавательная деятельность, ориентированная на их будущую профессию, для реализации которой в статье предлагается подробное описание различных видов групповой деятельности обучающихся, направленных на переработку иноязычной профессионально значимой информации в профессионально заданных ситуациях под руководством преподавателя. Опираясь на многолетний опыт педагогической деятельности в вузе, автор подтверждает, что такой вид занятия содействует приобретению обучающимися опыта профессиональной деятельности, формированию организационных и производственных навыков, обеспечива-
\end{abstract}

